\title{
Angioimmunoblastic T-Cell Lymphoma: A Diagnostic Challenge
}

\author{
Jorge Ocampo-Garza ${ }^{a}$ Maira Elizabeth Herz-Ruelas ${ }^{a}$ \\ Elias Eugenio González-Lopez ${ }^{c}$ Eric Eduardo Mendoza-Oviedob \\ Juana Irma Garza-Chapa ${ }^{a}$ Sonia Sofía Ocampo-Garza ${ }^{a}$ \\ Norma Elizabeth Vázquez-Herrera ${ }^{a} \quad$ Ivett Miranda-Maldonado $^{b}$ \\ Jorge Ocampo-Candiani ${ }^{a}$ \\ Departments of ${ }^{\mathrm{a}}$ Dermatology, ${ }^{\mathrm{b}}$ Pathology and ${ }^{\mathrm{c}}$ Hematology, University Hospital \\ 'Dr. José Eleuterio González', Universidad Autónoma de Nuevo León, Monterrey, Mexico
}

\section{Key Words}

Lymphoma · Angioimmunoblastic T-cell lymphoma · Cutaneous involvement · Epstein-Barr virus

\begin{abstract}
Angioimmunoblastic T-cell lymphoma (AITL) accounts for $15-20 \%$ of all peripheral T-cell lymphomas. It is a rare subtype of CD4 T-cell peripheral lymphoma that affects aged individuals, causing B symptoms, generalized lymphadenopathy and hepatosplenomegaly. Its pathogenesis is still unclear, but in some cases it has been associated with infection, allergic reaction or drug exposure. The majority of patients are diagnosed in an advanced stage and anthracycline based regimen is considered the first-line therapy. Skin involvement is not well characterized, occurring in up to $50 \%$ of patients and presenting as nonspecific rash, macules, papules, petechiae, purpura, nodules and urticaria. We present the illustrative case of a 55-year-old woman with an AITL who presented prominent skin findings, arthritis, lymphadenopathy and hypereosinophilia. Skin biopsy reported a T-cell lymphoma and the diagnosis of AITL was confirmed by an axillary lymph node biopsy, which was also positive for EpsteinBarr virus. Chemotherapy with $\mathrm{CHOP}-21$ and thalidomide was given, accomplishing complete remission after six cycles.

(c) 2014 S. Karger AG, Basel
\end{abstract}




\section{Introduction}

Angioimmunoblastic T-cell lymphoma (AITL) is a rare subtype of peripheral T-cell lymphoma [1, 2]. It accounts for $15-20 \%$ of all peripheral T-cell lymphomas and usually affects individuals in the seventh decade of life [3-5]. Approximately $20 \%$ of patients have associated autoimmune phenomena, such as circulating immune complexes, cold agglutinins, hemolytic anemia, rheumatoid factor and anti-smooth muscle antibodies [1]. AITL is a primary CD4 T-cell disorder with B-cell and endothelial cell dysregulation [4]. The clinical features include generalized lymphadenopathy, hepatosplenomegaly and B symptoms, including weight loss, fever and night sweats. The diagnosis is usually made by lymph node biopsy [6]. Skin involvement occurs in up to $50 \%$ of patients, but has not been well characterized $[4,7]$. We present a case of AITL with prominent skin findings.

\section{Case Report}

A 55-year-old female patient with a history of hypothyroidism presented with a 2-year history of an intermittent itchy rash that started on her neck and progressed to her arms, chest, abdomen and back. The patient was treated with oral prednisone and topical steroids which initially improved the lesions; however, they recurred with discontinuation of these medications.

Physical examination revealed multiple 2-4-mm erythematous, blanchable macules and papules on her trunk and extremities (fig. 1). She also had bilateral arthritis of the interphalangeal joints of the hands, wrists, elbows and knees as well as multiple enlarged axillary and inguinal lymph nodes. She presented with hypereosinophilia with an absolute count of $47,600 / \mu \mathrm{l}$. Bone marrow aspirate showed hypercellularity, with a myeloid:erythroid ratio of $5: 1 ; 65 \%$ of the cells were eosinophilic precursors with normal maturation. Eight-color flow cytometry revealed a population of immature T cells comprising $10.4 \%$ of total white blood cells with the following markers: CD3+, CD4-, CD5+, CD7+ dim, CD8-, CD34-, CD45+ and TdT-. A lesional skin biopsy reported T-cell lymphoma (diffusely positive CD3, CD4 and CD5 cells and focally positive CD8 and TIA-1 cells) (fig. 2). An axillary lymph node biopsy was consistent with AITL (CD3, CD4, CD5, CD7 and Epstein-Barr virus positive and CD8 and CD10 negative, with a CD21+ dendritic cell expansion) (fig. 3). A CT scan of the chest and abdomen was negative for mediastinal or abdominal adenopathy.

The diagnosis of an AITL, Cotswolds stage IVAD was made, with a Prognostic Index for AITL score of 1 (as described by Federico et al. [1]). Six cycles of CHOP-21 chemotherapy in addition to thalidomide $50 \mathrm{mg} /$ day from days 1 to 21 were administered. Complete remission was achieved, as documented by a CT scan 4 weeks after cycle 6 .

\section{Discussion}

In 1974, Frizzera et al. [8] described AITL as a reactive lymphoproliferative disorder of T lymphocytes. In 2001, the WHO classification of tumors of hematopoietic and lymphoid tissue listed AITL as a peripheral T-cell lymphoma [3, 4].

The pathogenesis of AITL remains unclear. In some cases the disease is preceded by an allergic reaction, infection or drug exposure $[2,6]$. A primary monoclonal and polyclonal T-cell proliferation secondary to Epstein-Barr virus infection also been suggested [9]. 
At the time of diagnosis, almost all patients present with advanced-stage disease (stages III-IV). In 70\% of patients manifestations include B symptoms, and $79 \%$ have splenomegaly $[8,10]$. Cutaneous lesions vary widely and can be encountered in approximately half of cases, presenting as a nonspecific rash, usually macules and papules, and less commonly purpura, urticaria, nodules or petechiae [7].

The differential diagnoses include infections, inflammatory or autoimmune diseases and other lymphoid neoplasms. A diagnosis can only be achieved by lymph node biopsy [6].

A variety of regimens have been used for the treatment of AITL. Among these, anthracycline-based therapy is considered the first-line treatment [11]. Patients treated with this regimen achieve complete remission in $61 \%$ of cases, with a 5 -year overall survival rate of $32 \%$ and a recurrence-free survival of only $18 \%$ [1]. When high-dose chemotherapy followed by autologous stem cell transplantation is administered, the likelihood of complete remission is improved $[12,13]$.

The molecular profile of the neoplastic T cells in AITL consists of CXCL13, bcl-6 and CD40L, shown in gene expression studies [6]. 95\% of AITL cases had increased expression of at least one of the following markers: SLAM-associated protein, programmed death-1 and c-Maf [14].

The diagnosis of AITL is very challenging, given the lack of clinical and histological diagnostic criteria. In one of the largest series of cases of peripheral T-cell lymphomas [1], agreement on diagnosis by expert hematopathologists was only $81 \%$. Cutaneous and histological findings may be nonspecific; therefore, clinical history, symptoms and complementary studies are very important. Our patient had been recently diagnosed with autoimmune hemolytic anemia, hypereosinophilic syndrome and arthritis; these, along with her signs and symptoms and besides skin and lymph node biopsies, led us to the correct diagnosis.

\section{Acknowledgement}

We would like to thank Dr. Amit G. Pandya, professor at UT Southwestern Medical Center at Dallas, Texas, for his thorough revision and editing of the manuscript.

\section{References}

1 Federico M, Rudiger T, Bellei M, Nathwani BN, Luminari S, Coiffier B, Harris NL, Jaffe ES, Pileri SA, Savage KJ, Weisenburger DD, Armitage JO, Mounier N, Vose JM: Clinicopathologic characteristics of angioimmunoblastic T-cell lymphoma: analysis of the international peripheral T-cell lymphoma project. J Clin Oncol 2013;31:240-246.

-2 Freter CE, Cossman J: Angioimmunoblastic lymphadenopathy with dysproteinemia. Semin Oncol 1993;20: 627-635.

-3 Yang QX, Pei XJ, Tian XY, Li Y, Li Z: Secondary cutaneous Epstein-Barr virus-associated diffuse large B-cell lymphoma in a patient with angioimmunoblastic T-cell lymphoma: a case report and review of literature. Diagn Pathol 2012;7:7.

4 Balaraman B, Conley JA, Sheinbein DM: Evaluation of cutaneous angioimmunoblastic T-cell lymphoma. J Am Acad Dermatol 2011;65:855-862.

5 Armitage J0: The aggressive peripheral T-cell lymphomas: 2013. Am J Hematol 2013;88:910-918.

6 Iannitto E, Ferreri AJ, Minardi V, Tripodo C, Kreipe HH: Angioimmunoblastic T-cell lymphoma. Crit Rev Oncol Hematol 2008;68:264-271.

7 Ohmatsu H, Sugaya M, Fujita H, Kadono T, Sato S: Primary cutaneous follicular helper T-cell lymphoma treated with allogeneic bone marrow transplantation: immunohistochemical comparison with angioimmunoblastic T-cell lymphoma. Acta Derm Venereol 2014;94:54-57.

-8 Frizzera G, Moran EM, Rappaport H: Angio-immunoblastic lymphadenopathy with dysproteinaemia. Lancet 1974;1:1070-1073. 
Ocampo-Garza et al.: Angioimmunoblastic T-Cell Lymphoma: A Diagnostic Challenge

-9 Jayaraman AG, Cassarino D, Advani R, Kim YH, Tsai E, Kohler S: Cutaneous involvement by angioimmunoblastic T-cell lymphoma: a unique histologic presentation, mimicking an infectious etiology. J Cutan Pathol 2006;33(suppl 2):6-11.

-10 Siegert W, Nerl C, Agthe A, Engelhard M, Brittinger G, Tiemann M, Lennert K, Huhn D: Angioimmunoblastic lymphadenopathy (AILD)-type T-cell lymphoma: prognostic impact of clinical observations and laboratory findings at presentation. The Kiel Lymphoma Study Group. Ann Oncol 1995;6:659-664.

11 Mosalpuria K, Bociek RG, Vose JM: Angioimmunoblastic T-cell lymphoma management. Semin Hematol 2014;51:52-58.

12 Schetelig J, Fetscher S, Reichle A, Berdel WE, Beguin Y, Brunet S, Caballero D, Majolino I, Hagberg H, Johnsen HE, Kimby E, Montserrat E, Stewart D, Copplestone A, Rösler W, Pavel J, Kingreen D, Siegert W: Long-term disease-free survival in patients with angioimmunoblastic T-cell lymphoma after high-dose chemotherapy and autologous stem cell transplantation. Haematologica 2003;88:1272-1278.

13 Kyriakou C, Canals C, Goldstone A, Caballero D, Metzner B, Kobbe G, Kolb HJ, Kienast J, Reimer P, Finke J, Oberg G, Hunter A, Theorin N, Sureda A, Schmitz N; Outcome-Lymphoma Working Party of the European Group for Blood and Marrow Transplantation: High-dose therapy and autologous stem-cell transplantation in angioimmunoblastic lymphoma: complete remission at transplantation is the major determinant of Outcome-Lymphoma Working Party of the European Group for Blood and Marrow Transplantation. J Clin Oncol 2008;26:218-224.

14 Roncador G, García Verdes-Montenegro JF, Tedoldi S, Paterson JC, Klapper W, Ballabio E, Maestre L, Pileri S, Hansmann ML, Piris MA, Mason DY, Marafioti T: Expression of two markers of germinal center T cells (SAP and PD-1) in angioimmunoblastic T-cell lymphoma. Haematologica 2007;92:1059-1066.
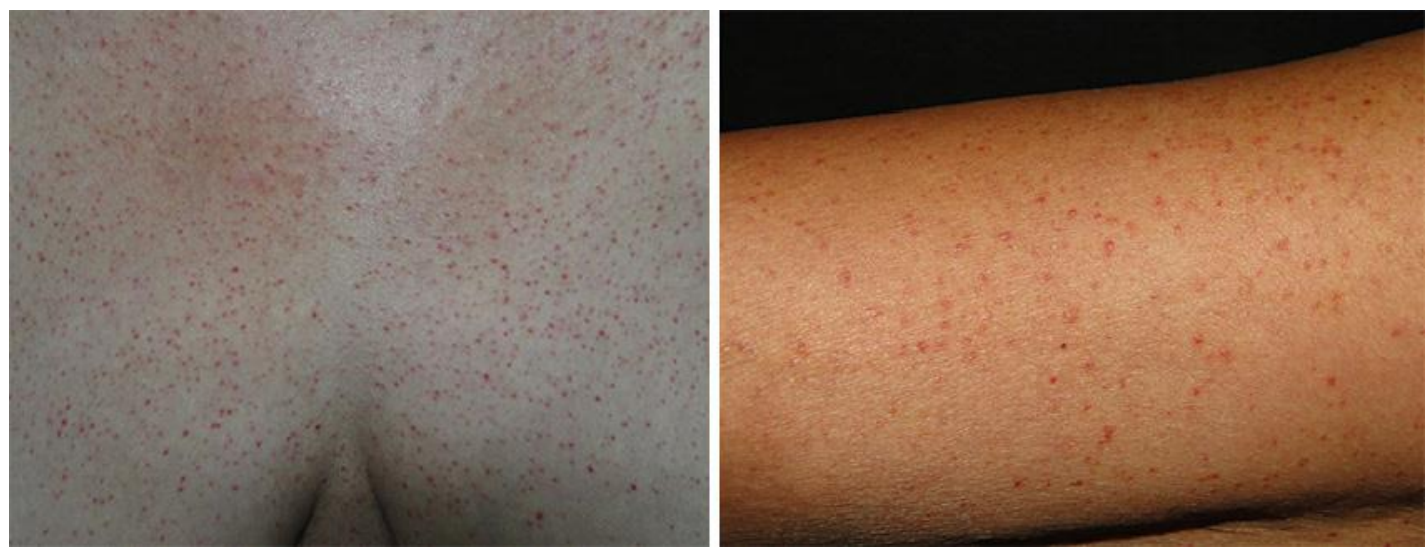

Fig. 1. Multiple 2-4-mm erythematous, blanchable macules and papules on the patient's trunk and extremities. 


\section{Case Reports in Dermatology}

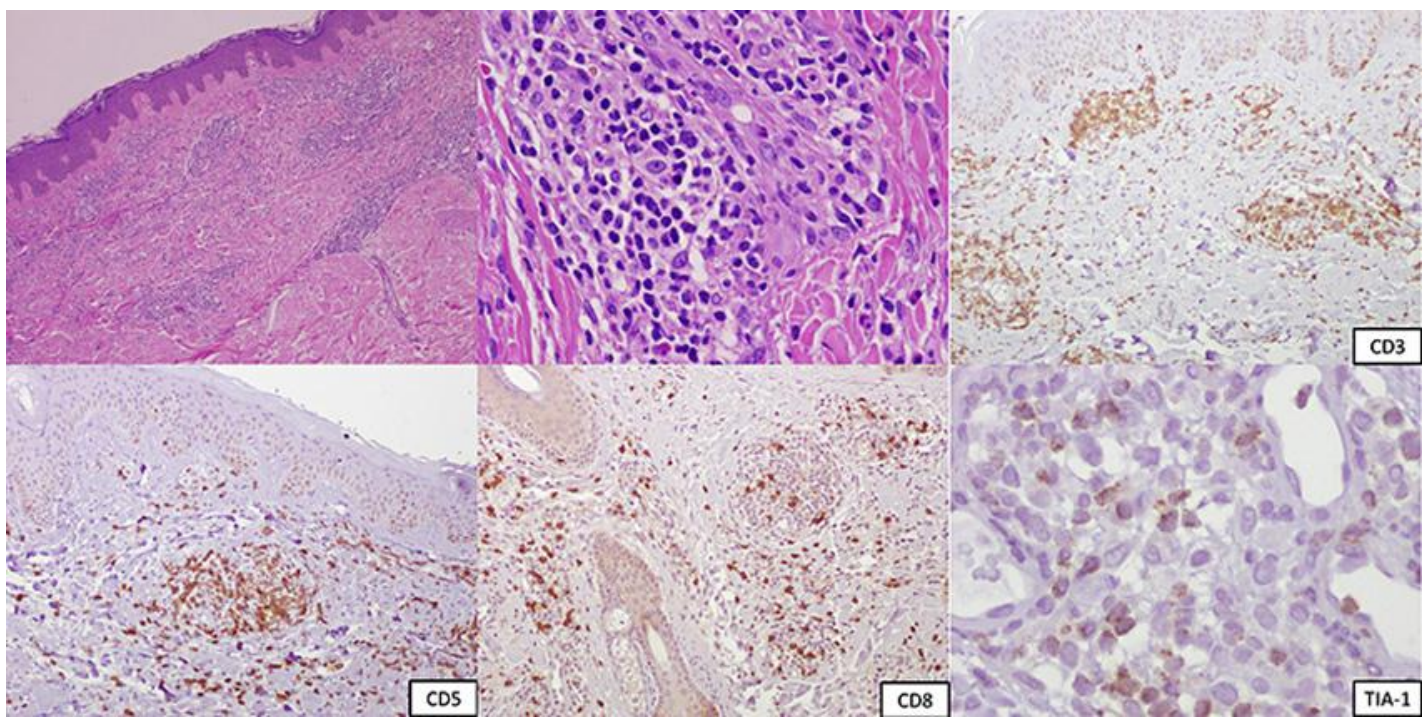

Fig. 2. Immunohistochemical staining of a skin biopsy showing diffusely positive CD3 and CD5 cells and focally positive CD8 and TIA-1 cells.

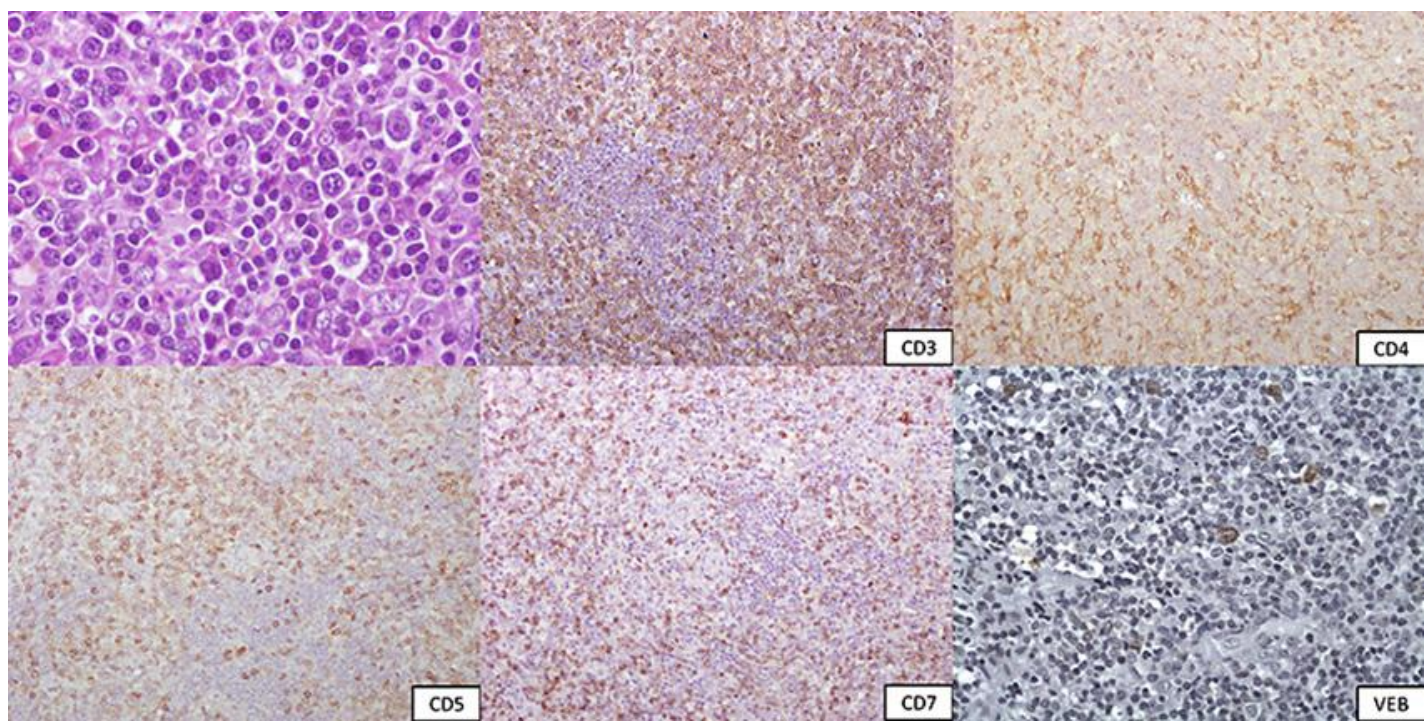

Fig. 3. Immunohistochemical staining of an axillary lymph node biopsy. CD3, CD4, CD5, CD7 and EpsteinBarr virus (VEB) were positive and CD8 and CD10 negative, with a CD21+ dendritic cell expansion. 